\title{
Study of Employee Engagement Initiatives at Vidarbha Industries Power Ltd. (Subsidiary of Reliance Power), Nagpur \\ ${ }^{1}$ Assistant Professor, Shri Ramdeobaba College of Engineering and Management, Nagpur \\ ${ }^{2}$ Senior HR Manager, Vidarbha Industries Power Ltd. (Reliance Power), Nagpur \\ Email:saorn@rknec.edu,rahul.miglani@relianceada.com
}

\section{Received: $20^{\text {th }}$ September 2018, Accepted: $11^{\text {th }}$ October 2018, Published: $31^{\text {st }}$ October 2018}

\begin{abstract}
This study is an exploratory study for understanding the various initiatives taken by Vidarbha Industries Power Ltd. (VIPL), Nagpur for employee engagement. The study will draw the relation of various engagement drivers and the engagement outcomes of the employees in the form of say, stay and strive. The successful achievement of engagement outcomes helps in fulfilling business outcomes in the broad areas of talent, operational, customer and financial. Various initiatives at VIPL for employee engagement will be studied and reported in the paper.

Some of the initiatives resulting in employee engagement are reward and recognition programmes, suggestion schemes, town hall interactions, HR policy as per the needs of the employees and many more. Every year, employee engagement survey is conducted by external agency.

Several employee engagement initiatives are taken which take care of family, team bonding, sports related activities and many more which will be discussed in the paper. The performance management system ensures timely reviews and is completely developmental in nature. This helps the employee to grow through practice of goal setting and constant monitoring and mentoring between the appraiser and appraisee. Going beyond the statutory compliances, VIPL believes in taking care of the health and welfare of all the workers and employees.

Overall, the engagement initiatives at VIPL results in increased engaged workforce thereby affecting the business of organization in a positive way.
\end{abstract}

\section{Keywords}

Aon Hewitt Model, Employee Engagement, Say, Stay and Strive

\section{Introduction}

Employee engagement is used interchangeably with employee satisfaction. But, it is not so. The concept of employee engagement is much deeper and includes the psychological involvement of the employee in the best possible way.

The Aon Hewitt Employee Engagement Model is widely used by companies to measure the employee engagement. The company also publishes an annual report by the name "Trends in Global Employee Engagement" since 2012 which reports the employee engagement percentages across the globe. The employee engagement score was $59 \%$ in 2011 and fluctuated in a similar range till 2017 wherein the score was $65 \%$. As per the report, the score is majorly driven by biggest markets in Asia and Africa. There are six employee engagement divers identified in the model namely, engaging leadership, talent focus, the work, the basics and agility. The priority as per the recent report is where employees are seeking exposure in senior leadership and strategy. As always, reward and recognition was the strongest driver of employee engagement.

Out of the 5 engagement drivers in the Aon Hewitt model; the basics and the work remain the basic drivers and agility, engaging leadership and talent focus remain the differentiators.

As per the report published by Aon Hewitt in 2018, there are various factors that affect the employee engagement trends such as political and economical stability. The employee engagement score of India in 2017 ranges from $68 \%$ to $73 \%$ with GDP growth of $3.5 \%$ to $5 \%$. The high employee engagement index can also be due economic stability in most mature countries and continued expansion in Asia.

The top most employee engagement opportunities identified globally as per ranking from top are rewards and recognition, senior leadership, career opportunities, employee value proposition and enabling infrastructure.

The employees in terms of their engagement levels can be actively disengaged, passive, moderately engaged or highly engaged.

In the research paper, the best HRM practices which lead to employee engagement will be discussed which are given as under: 
- Performance Management System and Reward and Recognition

The company has introduced SOUL program wherein goal setting is done in a participative way as per SMART framework. The objective of this program is to recognize \& appreciate the outstanding efforts of an employee by senior or junior colleagues or peers for accomplishing assignment and to create a culture of appreciation and recognition within the organization.

- Empower PULSE and Monthly Town Hall by Station Director

Empower pulse is an online employee concern program designed to encourage open communication between the employee and the senior management.

Monthly town hall is conducted with station director, in which station director presents overview of plant performance and monthly achievements and expectations from the employees are explained to them.

- Winds of Change

Some of the most successful and happiest organizations in the world are the ones that reinvent themselves and embrace change regularly. VIPL is having an open culture of communication where every employee's opinion matters and are heard, this has created extremely high levels of engagement among employees.

- Employee Friendly Company Policy

Good and employee friendly company policies improve employee morale, enhance image of the organization as well as brings more clarity in the working. Apart of regular, some more policies are for leave, working hours, Travel, PF, gratuity and may more.

- Annual Employee Engagement Survey by External Consultant

The organization conducts Employee engagement survey every year, from last 2 years . The objective of conducting employee engagement survey is create an opportunity for employees to have the feelings, they are impacting positive change in the organization.

- Employee Engagement Activities

To enhance the engagement of the employees various employee engagement activities are conducted such as sports, environment / safety / technical quiz / policy quiz, festival celebrations employees and family get together and many more.

- Health and Wellbeing of Employees and Workers

VIPL conducts various healthcare measures to preserve and promote health life of the employee, to prevent diseases and disability, and to felicitate early diagnosis of the treatment of illness. Any best practice is not completed without the welfare of the workmen. VIPL follows all the statutory provisions mentioned in law.

- Employee Welfare and Benefits

To eliminate the day to day hassles of the employee, thereby aid the employee to maintain a work-life balance. To create a culture of oneness by welfare activities for the employee, this would bring greater job satisfaction thereby improving the productivity, we provide bucket of initiatives.

\section{Material and Methods}

For the current study, data has been collected through interview method and secondary data published by the organization. The Aon Hewitt Employee Engagement Model is studied in detail with respect to the association of employee engagement drivers linked to engagement outcomes of say, stay and strive ending up in achievement of business outcomes.

The result and discussion portion will provide the employee engagement model implemented at VIPL. VIPL had conducted the employee engagement survey through an external agency and report is published. In the report of employee engagement survey 2018, a relation has been drawn between the engagement drivers and achievement of business outcomes.

VIPL is conducting Employee engagement survey every year since 2 years by external consultant. The objective of conducting survey is to create an opportunity for employees to have feelings, which impact positive change in the organization. With the survey, VIPL not only identifies best practices and where they can be shared, but also see where an improvement opportunity lies. High employee engagement is the outcome of a well-defined people strategy that is aligned to the business strategy of an organization.

\section{Results and Discussion}

At VIPL, there are seven engagement drivers resulting in say, stay and strive thereby achieving four business outcomes as in figure 1 . 


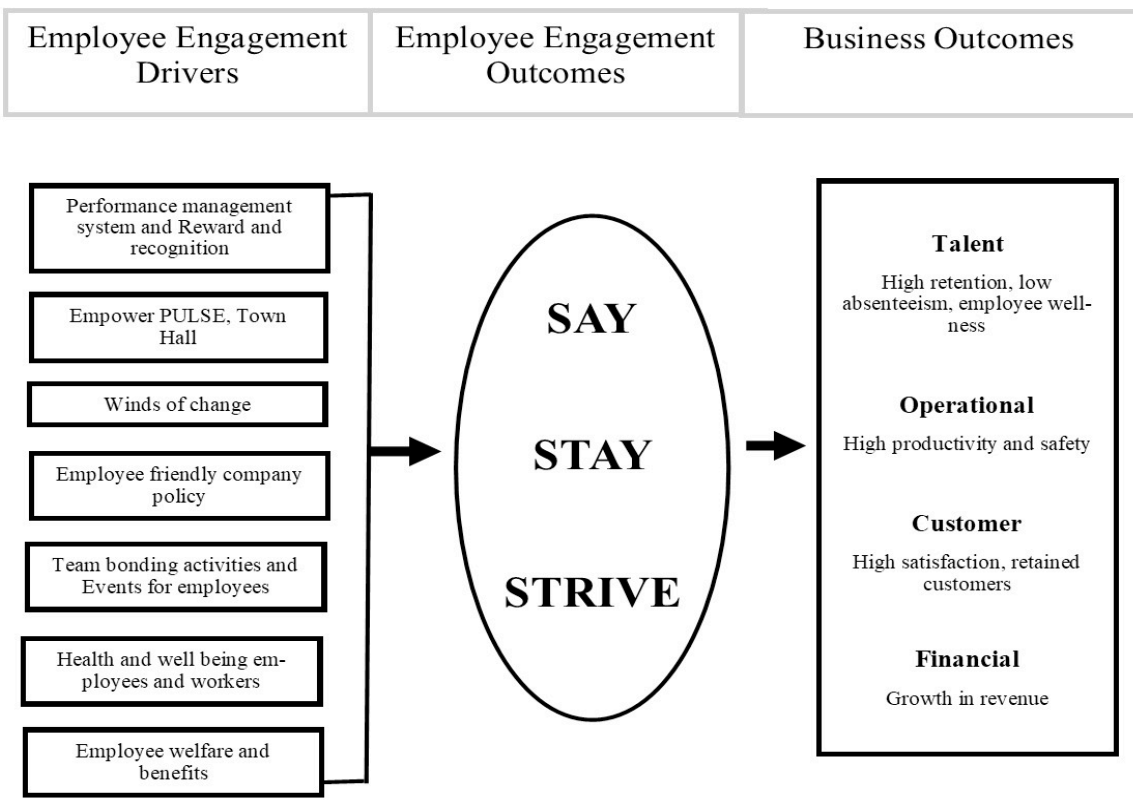

Figure 1: Employee Engagement Model at VIPL

\section{Employee Engagement Drivers at VIPL:}

- Performance Management System (PMS) and Reward and Recognition

VIPL believes in achievement of goals set in participative way and are SMART. Goal setting is aligned to VIPL's annual operating plan (figure 2). Review discussions are fixed between head and employees. It is coupled with midyear reviews and year end evaluation. Performance of employee is discussed at each stage and focus is always on development of the employees. Hurdles are identified and eliminated.

At VIPL, they understand how appraisal ratings can act as heartburn, thus, attempts are always made to ensure that PMS is fair and free from biases.

VIPL introduced a plan specifically for underperformers namely, 'Performance Improvement Plan' (PIP) to deal with under performance in organization. Main purpose is to encourage improvement and support employees by enabling them to achieve required performance standard. The identified employee is communicated about involvement in PIP followed by meeting with his appraiser and functional head. Employee are given mutually decided timelines and goals. It is followed by quarterly reviews. Final assessment is done at the year end. In case of non-improvement and low rating, it may result in demotion or salary cut. VIPL believes in giving fair chance to employees to enhance performance and achieve goals.

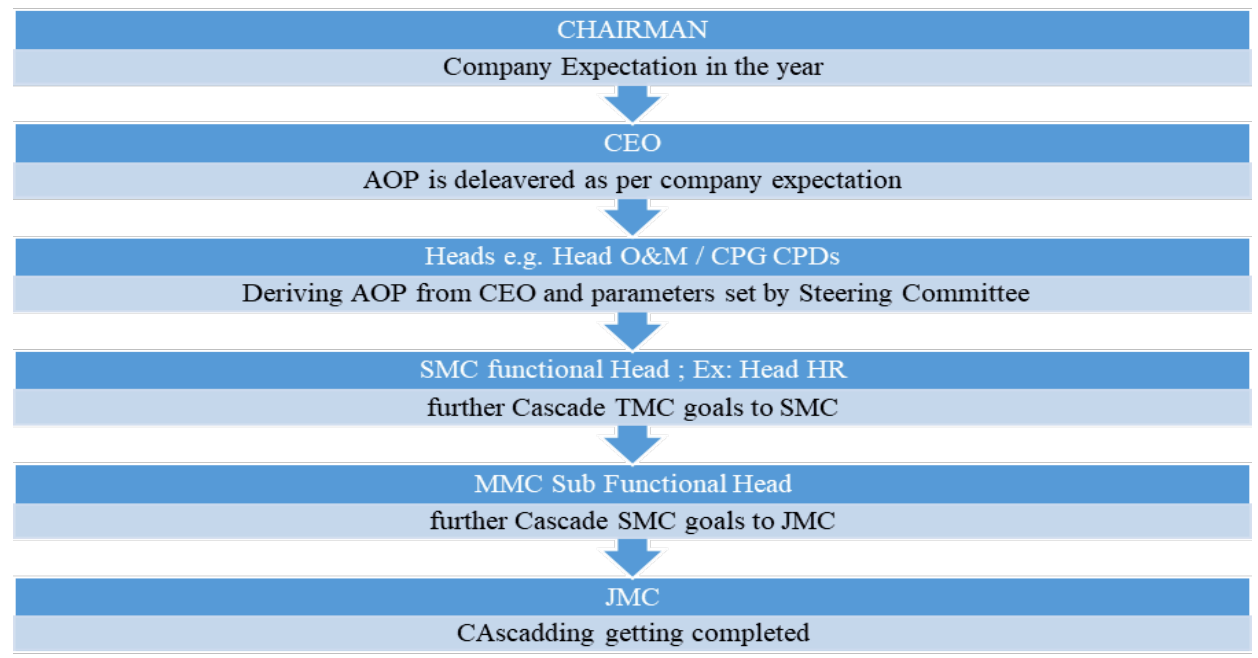

Figure 2: Goal Alignment with Annual Operating Plan at VIPL 
Reward and recognition is directly linked to employee performance. VIPL has well-defined reward and recognition program to recognize \& appreciate outstanding efforts of employee by senior, junior or peer for accomplishing assignment and create a culture of appreciation and recognition. Types of award are:

- Employee Appreciation wall

- Appreciate a Colleague

- Appreciation to employees in daily planning meeting

- Employee of the Month \& Quarter

- Bravo (On the spot reward)

- Platinum Star Achievement Award

- Chairman's yearly Award for outstanding performance

- Empower PULSE and Monthly Town Hall by Station Director

PULSE is an online employee concern program designed to encourage open communication between employees and senior management so that employees can raise issues without any fear of reprisal and ensure resolution within a specific time frame. All Zero tolerance issues (sexual harassment and integrity concerns) are escalated directly to top management.

To bridge link and to connect employee with organization objective, monthly town hall is conducted with station director, where overview of plant performance and monthly achievements and expectations are discussed, grievances are heard and redressed. Employees of any grade can interact with station director.

- Winds of Change: Suggestion Scheme

Employees are encouraged to write down suggestions and ideas in prescribed form and email to HR. The 'Star Suggestors' whose idea is accepted are rewarded every month with a gift voucher worth Rs. 1000 and their names are popularized across organization.

- Employee Friendly Company Policy

VIPL has many HR policies for the benefit of employees. Some of the policies are soft loan; appreciation \& recognition; group personal accident insurance \& term insurance; prevention, prohibition and redressed of Sexual Harassment at the workplace (POSH); job rotation; night shift allowances and compensatory off.

- Team Bonding and Events for Employees

To enhance employee engagement, various activities such as sports, environment, safety, quiz, festival celebrations, and family get together and many more are planned throughout the year.

- Health and Wellbeing of Employees and Workers

Objective is to preserve and promote health of employees, prevent diseases and disability, felicitate early diagnosis of diseases. VIPL has also provided mediclaim policy for hospitalization of employees to protect themselves from any unforeseen event. All legal compliances are done for healthcare of employees. Some more are mediclaim, yoga, special maternity benefit and half day nursing breaks to eligible female employees.

- Employee Welfare and Benefits

- Apart from statutory compliances, initiatives for contract workmen are ESIC "Pehechan Card" and "UAN Registration" camp, alcohol and tobacco de-addiction camps, trainings, weekly helpdesk, Health check-up camps, T-shirt distribution, tie-up with hospitals for treatment and felicitation of contract workman for exemplary work.

To create a culture of oneness and job satisfaction, VIPL takes following initiatives:

- Pick and drop facility for employees and their families from home to station or airport

- Site teams facilitates FMS like electrician, carpenter, plumber, civil workmen to all employees who stay in Butibori

- AC bus facility

- Flexi timing \& special leave for enabling employees to rest, rejuvenate and attend social, family commitments \& personal exigencies such as early pass, special extended maternity leave, paternity leave, special leave with pay and compensatory off for rotational shift and extra shift other than normal duty.

\section{Conclusion}

These initiatives in the form of HRM best practices towards employees have acted as employee engagement drivers for VIPL. The engagement drivers act as a driver for higher employee satisfaction which in turn result in three 
engagement outcomes of 'Say', 'Stay' and 'Strive' which are employees advocating the organization, staying with the organization and willingness to take extra efforts at the workplace respectively.
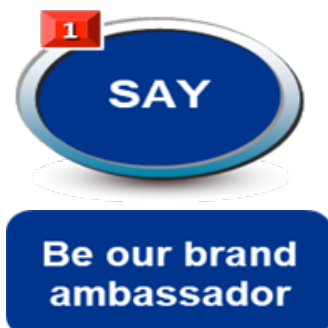

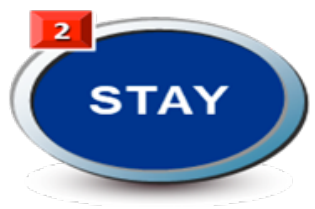

Stay

committed and loyal

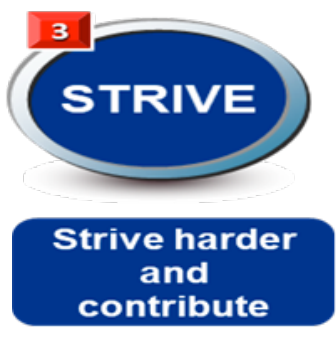

Figure 3: Employee Engagement Drivers at VIPL

This results in retention of talent, increase in operational efficiency, customer and client satisfaction with high retention of customer which finally results in increase in finance. VIPL is striving hard to enhance the employee loyalty and commitment to stay.

VIPL has been awarded with many awards nationally and internationally which include awards of highest level in the field of safety, environment, energy conservation, best employer brand, corporate social responsibility and best HR practices, learning and development and many more, which has brought a feeling of pride among the employees and enhanced their engagement level. VIPL has been able to achieve these high level of achievements and awards, because of their highly committed and Engaged Team. VIPL has also set a benchmark in all power projects and is one of the Best Power Projects in the country.

Hence it may be concluded that Employee engagement is directly linked with productivity and efficiency at VIPL.

\section{References}

1. http://www.aon.com/2018-global-employee-engagement-trends/index.html

2. McBain, R. (2007). The practice of engagement: Research into current employee engagement practice. Strategic HR review, 6(6), 16-19

3. Biswas, S., Varma, A., \& Ramaswami, A. (2013). Linking distributive and procedural justice to employee engagement through social exchange: a field study in India. The International Journal of Human Resource Management, 24(8), 1570-1587

4. Sarangi, S. (2012). An Exploratory Study of Employee Engagement Initiatives in the Indian Banking Sector. SIES Journal of Management, 8(1)

5. Robinson, D., Perryman, S., \& Hayday, S. (2004). The drivers of employee engagement. Report-Institute for Employment Studies

6. Rama Devi, V. (2009). Employee engagement is a two-way street. Human resource management international digest, 17(2), 3-4 